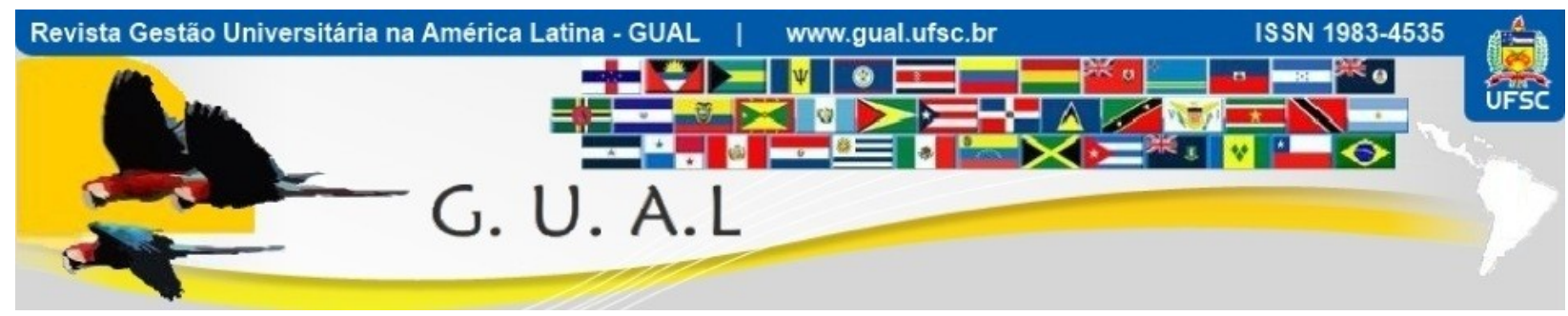

DOI: http://dx.doi.org/10.5007/1983-4535.2013v6n1p197

\title{
DESAFIOS E PERSPECTIVAS DA GESTÃO POR COMPETÊNCIA NA UNIVERSIDADE FEDERAL DE SANTA CATARINA
}

\section{CHALLENGES AND PROSPECTS OF MANAGEMENT BY COMPETENCY IN FEDERAL UNIVERSITY OF SANTA CATARINA}

Carla Cristina Dutra Burigo, Doutora Universidade Federal de Santa Catarina - UFSC carla.burigo@ufsc.br

Rogério João Laureano, Mestre Universidade Federal de Santa Catarina, UFSC rlaureano@reitoria.ufsc.br

Recebido em 23/outubro/2012

Aprovado em 21/dezembro/2012

Sistema de Avaliação: Double Blind Review

Esta obra está sob uma Licença Creative Commons Atribuição-Uso. 


\title{
RESUMO
}

O presente artigo tem como objetivo compreender como se desenvolveu o processo de implantação da Gestão por Competência na UFSC, no período de maio/2008 a maio/2012 com a homologação do Decreto $n^{0}$ 5.707, de 23 de fevereiro de 2006, (BRASIL, 2006) por meio da visão dos gestores administrativos. Com o advento do neoliberalismo, na década de 90, surgem novas práticas de gestão que buscam a competitividade e um comportamento estratégico dos trabalhadores em busca de resultados concretos. O Decreto $n^{0}$ 5.707/2006 (BRASIL, 2006), vem delimitar uma ação estratégica gerencial neste sentido, por meio da Gestão por Competência. Este estudo caracteriza-se por um estudo de caso de natureza qualitativa, fundamentado teoricamente e metodologicamente na busca das causas mediatas e imediatas do fenômeno investigado, com o intuito de compreender as representações historicamente intrínsecas no desenvolvimento deste fenômeno. A partir dos resultados desta pesquisa, é possível identificar como principais desafios diante do processo de implantação da Gestão por Competência na UFSC, uma maior interação no gerenciamento entre as ações da área de Gestão de Pessoas e a área de Planejamento, com vistas ao processo de desenvolvimento Institucional, bem como, delinear diretrizes identificando que universidade estamos construindo e que universidade desejamos construir.

Palavras-chave: Universidade pública. Gestão por competência. Processo de gestão.

\begin{abstract}
This article has the objective of enlighten how the process of implantation of management by competency in UFSC, between may/2008 to may/2012 with the homologation of the decree $n$. 5.707, of 2006 February 23th., (BRAZIL 2006) by the management administrators view. With the advent of the neoliberalism, in the 90's arise new management practices that search competitive and a strategic behavior of the workers looking for concrete results. The decree $\mathrm{n}$. 5.707/ 2006 (BRAZIL 2006), delimits a strategic management action on this way, by the competency management. This research characterizes by a qualitative case study, theoretically and methodologically grounded trying to find the mediate and immediate causes of the investigated phenomenon, wishing to comprehend the intrinsic historical representation on the development of this phenomenon. From the results of the research, it's possible to identify as the head challenges before the competency management implantation process on UFSC, a bigger interaction on the management between the actions of the people management area and the planning's, with eyes in the institutional development process, as well trace the directions identifying what university we are building and what university we wish to build.
\end{abstract}

Keywords: Public university. Competency management. Management process.. 


\section{INTRODUÇÃO}

O presente artigo tem por objetivo compreender como se desenvolveu o processo de implantação da Gestão por Competência na Universidade Federal de Santa Catarina (UFSC), no período de maio/2008 a maio/2012, com a homologação do Decreto $\mathrm{n}^{\mathrm{o}} 5.707$, de 23 de fevereiro de 2006, (BRASIL, 2006) por meio da visão dos gestores administrativos.

Com o advento do neoliberalismo, na década de 90, surgem novas práticas de gestão que almejam a competitividade e um comportamento estratégico dos trabalhadores em busca de resultados concretos. O Decreto $n^{0}$ 5.707/2006 (BRASIL, 2006), vem delimitar uma ação estratégica gerencial neste sentido, por meio da Gestão por Competência.

A essência do referido Decreto (BRASIL, 2006), é despertar a necessidade de implantar um modelo diferenciado de capacitação tradicional, realizando uma formação fundamentada no desenvolvimento de competências, no diálogo entre dirigentes e servidores, e no aprimoramento do pessoal.

Para o desenvolvimento do presente artigo, partimos de uma realidade concreta, ou seja, da Universidade Federal de Santa Catarina, com vistas a compreender os desafios do processo da Gestão por Competência a partir da publicação do Decreto $n^{\circ}$ 5.707/2006 (BRASIL, 2006). Na seqüência, estudamos o citado Decreto (BRASIL, 2006) e as condições em que foi publicado, considerando o contexto social, político e econômico, almejando compreender o processo da Política de Desenvolvimento Institucional da UFSC. Após, procuramos compreender como se desenvolveu historicamente o processo de gestão no serviço público, objetivando situar o processo de implantação da Gestão por Competência na UFSC. Por fim, retornamos ao ponto de partida, ou seja, à Universidade, visando desvelar as relações de mediações que esta caminhada pode propiciar na busca às respostas das inquietações que motivaram este estudo.

\section{A UNIVERSIDADE E OS DESAFIOS DA GESTÃO POR COMPETÊNCIA}

A política neoliberal na década de 90 determinou, e ainda vem determinando, as políticas públicas de educação superior do País. Como as demais instituições públicas federais do País, a Universidade Federal de Santa Catarina (UFSC) vivenciou a racionalização financeira como um matador silencioso em detrimento da ampliação das instituições de ensino superior privado, como um processo acrítico. 
Porém, como uma instituição social (CHAUÍ, 2003), a UFSC exprime de maneira determinada a estrutura e o modo de funcionamento da sociedade como um todo. Diante do seu legado histórico, esta Universidade é um marco na sociedade catarinense, tendo como parâmetro sua função social na concretização desta mesma sociedade que a fundamenta.

A UFSC, de acordo com o Plano de Desenvolvimento Institucional (PDI) (UFSC, 2010), tem como um dos maiores desafios, a consolidação da interiorização no Estado de Santa Catarina. Atualmente, conta com um corpo técnico ativo permanente de 5.363 servidores, entre docentes e técnico-administrativos em educação (UFSC, 2011a). Está localizada em Florianópolis, no bairro Trindade, e em três campi no interior do Estado: Araranguá, Curitibanos e Joinville.

Os quatro campi juntos envolvem mais de 44 mil alunos divididos em nível préescolar, ensino básico, graduação presencial e a distância, e pós-graduação, oferecendo 85 cursos e 93 habilitações (UFSC, 2011). Cada vez mais, a UFSC afirma-se como uma instituição plural e diversificada enfrentando a complexidade no contexto social onde está inserida, na qual para gerir tamanha estrutura inclui: Centro de Cultura e Eventos, Hospital, Clínicas, Departamento de Propriedade Intelectual, Fórum, Editora, Bibliotecas, Laboratórios, entre outros organismos que a permitem funcionar como uma cidade qualquer.

Historicamente, a UFSC se legitima no processo de desenvolvimento da sociedade catarinense, que tem um papel estratégico na formação e no desenvolvimento do conhecimento científico e tecnológico.

\section{GESTÃO E DESENVOLVIMENTO INSTITUCIONAL}

Para alcançar a plena execução de suas atribuições junto a sociedade, a Universidade Federal de Santa Catarina utiliza uma série de princípios que foram construídos historicamente, com vistas a fazer da Instituição uma referencia na sociedade catarinense, brasileira e internacional. Todos estes princípios, para além do Estatuto e Regimento da UFSC (UFSC, 1993) estão expressos no Plano de Desenvolvimento Institucional (UFSC, 2010) e refletem a missão e visão da Instituição.

Todavia, as políticas públicas educacionais refletem também no processo de desenvolvimento da gestão universitária. A partir da edição do Decreto no 5.707 (BRASIL, 2006) que instituiu a Política Nacional de Desenvolvimento de Pessoal imprimiu novas diretrizes à Universidade, principalmente no que se refere ao desenvolvimento permanente à 
adequação das competências requeridas dos servidores aos objetivos da instituição. As mudanças contidas no novo dispositivo legal atribuíram novos desafios à gestão universitária, em especial às áreas responsáveis pelo desenvolvimento e processo de formação.

A busca em atender às exigências das grandes e velozes transformações sociais, culturas e econômicas nos últimos anos, por meio das políticas públicas, obrigaram as instituições federais de ensino superior a reverem seus modelos internos de gestão, pressupondo a presença de trabalhadores preparados para este contexto. Deste modo, fazemse necessários a formação e o desenvolvimento contínuo dos servidores, trabalhadores, para que estes possam atuar com determinadas competências perante esta realidade.

Com a publicação do Decreto $n^{0}$ 5.707/2006 (BRASIL, 2006), a área da Gestão de Pessoas se volta para o desenvolvimento da competência com vistas à aquisição do conhecimento, habilidade e atitude do servidor para o exercício das funções públicas de sua responsabilidade, objetivando alavancar os resultados a serem alcançados institucionalmente. Essencialmente, o Decreto (BRASIL, 2006) busca alinhar, de forma mais efetiva, o potencial dos servidores com o cumprimento dos objetivos da instituição.

A UFSC como qualquer instituição, se constrói ou se destrói pelo desempenho das pessoas que nela trabalham, pois são elas o diferencial que impulsiona e, às vezes, até desestabiliza o desenvolvimento de qualquer instituição. Neste contexto, faz-se necessário considerar uma gestão voltada aos servidores, a partir da realidade os quais interagem no cotidiano universitário (BÚRIGO, 2011).

O cotidiano universitário é marcado por anseios, desejos e necessidades que perpassam diariamente as unidades administrativas e universitárias da UFSC, onde os servidores nem sempre têm as respostas para tais demandas implicando, muitas vezes, em informações e ações desarticuladas, com perda da noção da realidade interna e externa da Universidade.

Contudo, a Gestão por Competência, com o advento do Decreto n ${ }^{\circ}$ 5.707/ 2006 (BRASIL, 2006), vem se apresentando como um desafio, de modo a rever as práticas desenvolvidas na área de Gestão e de Desenvolvimento Institucional.

\section{O DECRETO No 5.707/ 2006 (BRASIL, 2006)}

De acordo com a literatura investigada, os avanços observados nas últimas décadas, têm provocado nas instituições, sejam elas públicas ou privadas, a busca de formas de gestão 
que objetivem melhorar o nível do desempenho dos seus servidores, com vistas a alcançar melhores resultados e ir ao encontro da missão institucional.

No Serviço Público Federal esta busca de novas formas de gestão, não é diferente. A partir da década de 90, com as profundas mudanças ocorridas nos cenários nacional e internacional, o Estado teve a necessidade urgente de buscar novos caminhos. Neste contexto, de acordo com Brito (2005, p. 37):

Torna-se fundamental para a instituição se apropriar de uma dimensão da realidade que é complexa e de difícil acesso e que se refere à cultura organizacional e à subjetividade do trabalhador para obter o comprometimento para a construção dos novos modelos.

Há, contudo, um grande esforço no sentido de mudar do antigo modelo burocrático para uma nova prática de gestão e, para tanto, algumas questões cruciais precisam ser enfrentadas. Um dos potenciais caminhos a ser percorrido é o aprimoramento da Gestão de Pessoas, tendo como premissa sua valorização e a modernização dos processos de trabalho.

O Governo Federal, por meio do Decreto $n^{0}$ 5.707, de 23 de fevereiro de 2006 (BRASIL, 2006), instituiu a política e as diretrizes para o desenvolvimento de pessoal da Administração Pública Federal direta, autárquica e fundacional, objetivando melhorar os serviços prestados ao cidadão. A Gestão por Competência é um novo modelo de gerenciamento que vem sendo adotado pelas Instituições Públicas de Ensino Superior com base no citado Decreto (BRASIL, 2006).

Cabe destacar que, o fato da Gestão por Competência ser um modelo relativamente recente e complexo, tem contribuído para a manutenção das incertezas quanto à factibilidade e a maneira de se aplicar esta proposta no serviço público. E isto se reflete, na quantidade de publicações produzidas para tratar deste tema, em relação às produzidas no setor privado. Os resultados apontados pela literatura da Gestão por Competência no setor privado servem de reflexão, porém eles não podem ser exportados diretamente para o setor público, pois precisam ser repensados observando as particularidades da realidade do setor público.

Neste contexto, o desafio que se coloca à Administração Pública, mais do que apropriação do conceito de competência, é o desafio cultural de transformar estruturas burocráticas, hierarquizadas e que tendem há um processo de insulamento, em instituições flexíveis e empreendedoras. No setor público, mais do que em qualquer outro setor, a base fundamental da abordagem de competência deixa de ser o desenho de cargos e passa a ser um 
conceito dinâmico de habilidade e competências necessárias ao cumprimento da missão da instituição.

A expressão "competência" surgiu na Idade Média e, na linguagem jurídica, segundo Isambert (1997), diz respeito à faculdade atribuída a alguém ou a uma instituição para apreciar e julgar determinada questão. Com o advento da administração científica, passou a ser utilizada para qualificar o indivíduo capaz de realizar determinados trabalhos.

De acordo com Fleury (2001), a competência é o estado de ser funcionalmente adequado com bom nível de qualidade, com conhecimento, julgamento, habilidades ou força para a realização de uma determinada tarefa. Tal definição menciona dois pontos principais ligados à competência: conhecimento e tarefa.

Para Carvalho et al. (2009), o conceito de competência possui respaldo internacional e vem sendo assumido como a oportunidade de aproximação entre a educação e o mundo do trabalho, fazendo do trabalho um princípio educativo.

Algumas concepções valorizam determinadas competências, Zarifian (2001), por exemplo, ao definir competência, baseia-se na premissa de que, em ambiente dinâmico e competitivo, não é possível considerar o trabalho como um conjunto de tarefas ou atividades pré-definidas e estáticas. Para o autor, a competência deve representar o comprometimento com a situação de trabalho, complexa com o uso de uma reflexividade no trabalho, que permita ao profissional lidar com eventos ocasionais, inesperados, exigindo do trabalhador o saber fazer, estimulando a capacidade de raciocínio e a criatividade, assim como a sensibilidade e a vontade de aprender, desenvolvendo a capacidade de visualizar oportunidades e problemas por ângulos diferentes.

O desenvolvimento das competências, não pode transformar o trabalhador em um robô que obedece cegamente às ordens. Entretanto, para que possa tomar iniciativa, ele precisa desenvolver a capacidade de imaginação e de invenção e, dessa forma, abordar o trivial e o imprevisto de maneira adequada e inovadora. Trata-se de assumir a responsabilidade pela avaliação da situação, pela iniciativa que pode exigir e pelos efeitos que vão decorrer dessa situação (ZARIFIAN, 2001).

O objetivo da Gestão por Competência conforme Brito (2005), não é impor uma competência específica à instituição através de mudanças estruturais, mas potencializar a perspectivas por meio das ações de cada gerente e servidor. Isso significa estabelecer um 
processo de participação envolvendo as unidades de planejamento e de desenvolvimento e isto só se materializa a partir do engajamento de todos.

Isto posto, com base na pesquisa realizada e sem o objetivo de sermos exaustivos, consideramos que competência seria o conjunto de características individuais (conhecimentos, habilidades e atitudes) que, em um contexto institucional/organizacional particular, possibilita a realização de atividades profissionais segundo certas diretrizes, para produzir resultados que satisfaçam critérios de desenvolvimento da instituição/organização onde o trabalhador/servidor esteja inserido.

Historicamente no processo de desenvolvimento da gestão pública, têm-se as práticas de gestão voltadas ao patrimonialismo e à burocracia. A prática de gestão patrimonialista historicamente deu lugar à prática de gestão burocrática. Entretanto, diante das transformações sociais a partir do Século XX, surgiu a necessidade de otimização da máquina pública para atender ao cidadão. Esta prática, em alguns casos, também já não atende a certas necessidades em certos setores da administração, desaparecendo gradativamente, embora em outros setores, ainda seja indicada e preservada (BRESSER PEREIRA, 1996).

Para Guimarães et al. (2000), o setor público tem procurado adotar uma Gestão por Competência como alternativa de gestão flexível e empreendedora que possibilite um melhor nível de qualidade e eficiência dos serviços públicos. Dentre os vários fatores que levam a este processo, destacam-se: a necessidade de adequação dos recursos públicos aos níveis crescentes de exigência da sociedade e a possibilidade da utilização de novas ferramentas gerenciais e administrativas.

Neste contexto, a gestão flexível está associada à idéia de inovação, mudança, agilidade e de capacidade de adaptação, de forma que a instituição possa responder com eficiência às demandas da sociedade (GUIMARÃES et al., 2000).

Contudo, como negação, a gestão essencialmente burocrática e as transformações ocorridas na sociedade a partir do Século XX, propõem-se uma gestão flexível e mais humanitária, onde o trabalhador exerça um papel como parte da instituição e não apenas como um indivíduo à parte dela.

Acreditamos que a abordagem da Gestão por Competência por meio da publicação do Decreto $n^{0}$ 5.707/2006 (BRASIL, 2006) vem contextualizando um novo cenário para a gestão pública, essencialmente para a Gestão de Pessoas, uma vez que sua base de sustentação está no conhecimento, nas habilidades e atitudes requeridas pela instituição. Para tanto, faz-se 
pertinente uma reflexão sobre a flexibilização da lógica trabalhista, o envolvimento e a responsabilização permanente do trabalhador em seu processo de desenvolvimento, alicerçado ao da instituição.

Consideramos que a flexibilização na gestão pública, principalmente no que tange às relações de trabalho, potencializa a subjetividade do trabalhador, o desenvolvimento do trabalho em equipe, o resgate da humanização das relações de trabalho, negando a gestão pública essencialmente burocrática.

\section{CAMINHO METODOLÓGICO PERCORRIDO}

Com vistas a atender ao objetivo inicialmente proposto no presente artigo, foi realizada uma entrevista semi-estruturada, com os gestores administrativos da Universidade, da área de Planejamento e de Gestão de Pessoas, abrangendo diferentes níveis hierárquicos da Instituição, buscando representar o ambiente estudado.

Fizeram parte desta amostra, cargos contemplados na gestão da UFSC de maio/2008 a maio/2012 da área de Planejamento e de Gestão de Pessoas: Pró-Reitor de Desenvolvimento Humano e Social (PRDHS), Chefe da Divisão de Capacitação e Afastamento para Formação (DCAF) do Departamento de Desenvolvimento de Potencialização de Pessoas (DDPP/PRDHS), Secretário de Planejamento e Finanças (SEPLAN) e Diretor do Departamento de Planejamento (DPL/ SEPLAN).

A opção pela definição desta amostra justifica-se por considerar que estes gestores, por meio de suas práticas laborativas, podem trazer elementos de análise com vistas a atender as indagações do objetivo inicialmente proposto.

As atividades laborativas destes gestores estavam alicerçadas ao processo de capacitação e planejamento da Instituição investigada:

- Pró-Reitor de Desenvolvimento Humano e Social: coordenar e acompanhar o desenvolvimento das políticas de potencialização de pessoas, destinadas aos servidores docentes e técnico-administrativos em educação (UFSC, 2012a).

- Chefe da Divisão de Capacitação e Afastamento para Formação (DCAF/DDPP/PRDHS): desenvolver em articulação com os órgãos competentes e em consonância com o Plano de Desenvolvimento Institucional, a política de capacitação dos servidores da UFSC (UFSC, 2012a).

- Secretário de Planejamento e Finanças (SEPLAN): coordenar o planejamento institucional, ocupação física e projetos de arquitetura e engenharia, a gestão 
orçamentária, financeira, contábil, a avaliação institucional, bem como a elaboração da prestação de contas anual (UFSC, 2012b).

- Diretor do Departamento de Planejamento (DPL/SEPLAN: estabelecer diretrizes e propor normas aplicáveis às atividades de planejamento institucional, observando a legislação em vigor; coordenar o planejamento institucional, por meio de seus instrumentos de gestão; orientar e apoiar as atividades de elaboração de planejamento; e acompanhar a execução do planejamento institucional (UFSC, 2012b).

A pesquisa caracteriza-se por ser qualitativa, pois buscou descrever, interpretar e explicar como se manifestam os fatores e fenômenos da realidade investigada, procurando desvelar a relação e conexão do fenômeno investigado com outros, sua natureza e características. Cabe salientar que com base na pesquisa bibliográfica foi possível fundamentar e diagnosticar a situação existente do fenômeno investigado, bem como justificar os limites e contribuições da própria pesquisa.

\section{CONSIDERAÇÕES FINAIS}

Resgatando o objetivo inicialmente proposto, ou seja, compreender como se desenvolveu o processo de implantação da Gestão por Competência na UFSC, no período de maio/2008 a maio/2012, com a homologação do Decreto $n^{0} 5.707$ (BRASIL, 2006), por meio da visão dos gestores administrativos, é possível afirmarmos que é um desafio o processo de implantação da Gestão por Competência, que perpassa essencialmente pelo processo de formação dos gestores da área de Gestão de Pessoas e de Planejamento da Instituição, bem como, pela articulação entre estas áreas visando o desenvolvimento institucional.

Na visão dos gestores, a Universidade é responsável pela produção e socialização do conhecimento. Todavia, esta concepção de universidade concebida como produtora e socializadora de conhecimento necessita ser repensada na relação de concepção e na prática laborativa dos seus gestores, pois há um claro desconhecimento da necessidade de articulação entre as áreas em estudo (Gestão de Pessoas e Planejamento), atuando como feudos isolados podendo a vir comprometer a própria concepção que os gestores têm de Universidade.

Isto posto, a concepção de universidade pública exposta pelos gestores, perpassa pela produção e socialização do conhecimento, como instituição social, pública e publicizada em sua ação. Contudo, para que esta concepção se materialize, os gestores vivenciam uma contradição, ou seja, ao mesmo tempo em que esta Universidade é concebida como produtora 
de conhecimento, de formação para atender a sociedade, ela necessita ser repensada quanto ao processo de formação dos seus gestores e às condições de trabalho a eles propiciadas.

O processo de formação do gestor, também é um dos elementos decisivos na relação que este mantém com o seu trabalho. Por outro lado, esta formação é determinada pela interação do gestor com as condições existentes de trabalho, a partir das possibilidades concretas, propiciadas ao gestor pela sua formação (CHAUÍ, 2003).

O abismo existente entre a área de Gestão de Pessoas e a área de Planejamento da Instituição, acaba por comprometer o alcance das finalidades institucionais, implicando em uma atuação fragmentada e desarticulada, prejudicando a definição das políticas para o Desenvolvimento Institucional. Em outras palavras, há carência de um elo que integre as estratégias e as práticas institucionais, cada uma em seu âmbito e com mecanismos distintos. Salvo pontuais iniciativas, não possuem aproximação que permita incrementar o processo de implantação da Gestão por Competência.

No que tange à Política de Desenvolvimento Institucional, na concepção dos entrevistados, há um vazio no processo de desenvolvimento, tendo como parâmetro as diretrizes do Decreto $n^{0}$ 5.707/2006 (BRASIL, 2006), devido a não articulação entre a área de Gestão de Pessoas e a área de Planejamento, o desconhecimento do próprio Decreto (BRASIL, 2006), por parte dos gestores, bem como, a não definição das competências institucionais.

Entretanto, a implantação da Gestão por Competência, sem dúvida, propiciará um novo olhar sobre o processo de gestão. Para tanto, se faz necessário o conhecer, o desvelar a essência desta política instituída pelo Governo Federal, que não está dissociada das diretrizes produtivista neoliberal.

Há outro abismo a ser vencido, ou seja, as condições reais de implantação do modelo de Gestão por Competência em uma instituição pública de ensino superior, diante da sua essência de gestão burocrática. Ou seja, estamos atrelados, por exemplo, aos cargos definidos na década de 70, onde não temos autonomia para modificar.

Outro dilema estrutural burocrático da universidade é o próprio processo de formação dos servidores técnico-administrativos em educação propiciado pela Instituição, que muitas vezes vai além das exigências do cargo. Ou seja, forma-se o servidor técnico-administrativo em educação, mas este processo de formação é negado muitas vezes, diante das atribuições do 
cargo e do formalismo da lei que impede na essência o desenvolvimento de novas competências do servidor em comento.

Todavia, a essência deste modelo da Gestão por Competência, apresenta claros dilemas produtivistas da iniciativa privada, onde a produção é o produto final almejado, de uma forma acrítica ao contexto universitário, com claro desconhecimento da realidade onde está inserida.

Com o advento do neoliberalismo, como um processo histórico, novas concepções de trabalho e de relações de trabalho, foram se estruturando refletindo nas ações gerenciais das organizações e instituições como forma de se adequarem as exigências sociais, políticas e econômicas que vem se constituindo.

De acordo com Brito (2005), este novo modelo significa também a passagem da concepção de trabalhador objeto, no sentido de que apenas executa as determinações da cúpula da Instituição, para a concepção de trabalhador sujeito, no sentido em que tem autonomia para planejar o próprio trabalho, criar e inovar à serviço do capital. Desta forma, ocorre à valorização da subjetividade, das competências subordinada a lógica do capital.

Contudo paradoxalmente, ao mesmo tempo em que o trabalhador tem valorizado a sua competência e a necessidade de sua inteligência é explicitada, este mesmo trabalhador não tem condições de trabalho adequadas e apropriadas para o desenvolvimento deste seu potencial.

A flexibilização nas relações de trabalho seria quiçá, o grande salto qualitativo ao modelo da Gestão por Competência nas universidades públicas federais, e na UFSC. Para tanto, se faz necessário repensar na estrutura burocrática que envolve esta Instituição, que é legitimada pelo formalismo das legislações vigentes.

Isto posto, diante de todo este contexto apresentado, os resultados deste estudo apontam, para que haja essencialmente um salto qualitativo no processo de desenvolvimento de implantação da Gestão por Competência na UFSC, se faz pertinente uma maior interação no gerenciamento de suas ações entre a área de Gestão de Pessoas e de Planejamento. Diante das entrevistas realizadas com os gestores, não podemos negar o esforço destas áreas com vistas ao desenvolvimento institucional. Porém, o que defendemos é a integração destas áreas, com objetivos concretos de realização de um trabalho conjunto, com diretrizes delineadas na eminência de refletir sobre que universidade estamos construindo e que universidade desejamos construir. 
Acreditamos que a Universidade precisa manter seus profissionais em constante processo de atualização e formação, para legitimar sua relação com a sociedade. Porém, tal relação não se constitui de causa e efeito. Ela é medida por um processo de contradição, com a sustentação e oposição a esta mesma sociedade, daí a necessidade da Instituição manter-se atenta aos movimentos desta sociedade, com olhar criterioso para os caminhos pelos quais a Universidade pretende seguir.

Contudo a formação, a capacitação dos servidores, perpassa por um processo permanente e deliberado de aprendizagem, com o propósito de contribuir para o desenvolvimento de competências e para o exercício das atividades, aliadas ao processo de gestão e ao desenvolvimento institucional, a partir de um sistema de planejamento integrado.

Todavia, neste contexto, se faz necessário um olhar mais amplo sobre as potencialidades e individualidades dos servidores por meio da Gestão de Pessoas, bem como, das condições necessárias para a realização desta ação, negando a gestão burocrática, com uma gestão mais flexível situando o servidor como sujeito do seu trabalho e não mero objeto da sua produção.

Acreditamos que se o planejamento institucional não estiver alinhado às políticas de capacitação, pouco poderá ser feito, no que tange ao processo de desenvolvimento institucional. A Instituição, ao tratar o planejamento estratégico de forma elitista, centrado na alta administração, sem a participação de todos os servidores, sem a definição das competências institucionais de forma coletiva e participativa, pouco se avançará neste sentido. E este comportamento é materializado nos resultados que este estudo apresenta, quando identifica o abismo existente entre o planejamento institucional e a política de capacitação, desenvolvido na UFSC.

A Gestão por Competência não é uma opção para a Universidade, é um delimitador definido por Decreto (BRASIL, 2006), que deve ser implementada, independente da realidade da Instituição. Contudo, por este modelo ser relativamente recente, complexo e desconhecido, na gestão pública tem contribuído para a manutenção das incertezas por parte dos gestores.

Isto posto, propomos como perspectivas ou possíveis caminhos para o fortalecimento do processo da Política de Desenvolvimento da UFSC, por meio da Gestão por Competência, à Administração Central da Universidade:

- Articular junto aos órgãos competentes, com vistas a rever a legislação vigente de modo a adequar a estrutura burocrática das universidades públicas federais a 
este novo modelo de gestão, homologado com base no Decreto $\mathrm{n}^{\mathrm{o}}$ 5.707/ 2006 (BRASIL, 2006).

- Definir as competências institucionais em um trabalho conjunto com a comunidade universitária.

- Fortalecer o processo de formação do servidor com vistas a desvelar as competências individuais necessárias para o desenvolvimento das competências institucionais.

- Promover ações compartilhadas com vistas ao desenvolvimento institucional, entre a área de Gestão de Pessoas e de Planejamento da Instituição.

- Promover a divulgação e a sensibilização do Decreto $n^{0}$ 5.707/2006 (BRASIL, 2006), visando uma melhor compreensão por parte da comunidade universitária.

- Desenvolver políticas institucionais voltadas para o processo de formação dos servidores com vistas a compreender as políticas públicas implementadas pelo Governo Federal, e dos aspectos sociais, políticos e econômicos que as permeia.

- Repensar as ações da área de Gestão de Pessoas, as legislações internas vigentes de modo a dinamizar e sistematizar as diversas práticas nesta área sejam elas de seleção, avaliação e capacitação do servidor, tendo por base o modelo de Gestão por Competência.

- Capacitar os Gestores diante do processo de desenvolvimento das políticas públicas educacionais, destinadas às universidades públicas federais, que se materializam por meio de leis, decretos, portarias ministeriais, entre outros. Em especial como objeto de estudo do presente artigo, a capacitação referente ao Decreto $^{\circ}$ 5.707/ 2006 (BRASIL, 2006b).

Sem dúvida, a Gestão por Competência constitui um desafio para qualquer instituição, devido às demandas institucionais que ela impõe. A implementação do Decreto $\mathrm{n}^{0}$ 5.707/ 2006 (BRASIL, 2006), materializa estas demandas, na medida em que: exige do gestor conhecimento do referido Decreto (BRASIL, 2006); se faz necessário a disseminação da sua concepção junto à comunidade universitária; e, delimita o alinhamento dos objetivos individuais com os objetivos institucionais.

\section{REFERÊNCIAS}

BRASIL. Decreto $\mathbf{n}^{\mathbf{0}} \mathbf{5 . 7 0 7}$, de 23 de fevereiro de 2006. Institui a política e as diretrizes para o desenvolvimento de pessoal da administração pública federal direta, autárquica e fundacional, e regulamenta dispositivos da Lei $\mathrm{n}^{\circ}$ 8.112, de 11 de dezembro de 1990. 2006. Disponível em: <http://www.planalto.gov.br/ccivil_03/Ato2004-2006/2006/Decreto/ D5.707.htm>. Acesso em: 14 fev. 2012. 
BRESSER PEREIRA, Luiz Carlos. Gestão do setor público: estratégia e estrutura para um novo Estado. In: BRESSER PEREIRA, Luiz Carlos; SPINK, Peter K. (Org.). Reforma do Estado e administração pública gerencial. 2. ed. Rio de Janeiro: Editora FGV, 1996.

BRITO, Lydia Maria Pinto. Gestão de competência, gestão do conhecimento e organizações de aprendizagem: instrumento de apropriação pelo capital do saber do trabalho. Fortaleza: Imprensa Universitária, 2005.

BÚRIGO, Carla Cristina Dutra; LOCH, Clésar Luiz. De recursos humanos ao processo de desenvolvimento humano e social um olhar sobre a Gestão de Pessoas na Universidade Federal de Santa Catarina. Revista Reflexão e Ação, v. 19, n. 1, 2011. Disponível em: $<$ http://online.unisc.br/seer/index.php/reflex>. Acesso em: 14 fev. 2012.

CARVALHO, Antônio Ivo de et al. Escolas de governo e gestão por competência: mesaredonda de pesquisa-ação. Brasília, DF: ENAP, 2009.

CHAUÍ, Marilena. A universidade pública sob nova perspectiva. Revista Brasileira de Educação, São Paulo, n. 24, p. 5-15, set./dez. 2003.

FLEURY, Maria Tereza Leme; FLEURY, Afonso. Construindo o conceito de competência. 2001. Disponível em: $<\mathrm{http}: / / w w w . s c i e l o . b r /$ scielo.php?pid=S1415 65552001000500010\&script=sci_arttext $>$. Acesso em: 14 fev. 2011.

GUIMARÃES, Tomás de Aquino et al. Forecasting core competencies in R\&D environment. In: INTERNATIONAL CONFERENCE ON MANAGEMENT OF TECHNOLOGY, 9., Feb. 2000, Miami. Proceedings. Miami: International Association for Management of Technology, 2000.

ISAMBERT-JAMATI, Viviane. O apelo à noção de competência na revista L'Orientation Scolaire et Profissionelle: da sua criação aos dias de hoje. In: ROPÉ, Françoise; TANGUY, Lucie (Org.). Saberes e competências: uso de tais noções na escola e na empresa. Campinas: Papirus, 1997.

UFSC. Estatuto e Regimento Geral. 1993. Disponível em: <http://estrutura.ufsc.br/ files/2011/04/estatuto_ufsc_agosto2008.pdf >. Acesso em: 14 fev. 2012.

. Plano de desenvolvimento institucional 2010-2014. 2010. Disponível em:

$\overline{<\mathrm{http}}$ //pdi.paginas.ufsc.br/>. Acesso em: 14 fev. 2012.

UFSC em números. 2011. Disponível em: $<$ http://www.pip.ufsc.br/arquivos /UFSC_NUMEROS_00_09.pdf $>$. Acesso em: 11 abr. 2012.

.P RDHS - Pró-Reitoria de Desenvolvimento Humano e Social. 2012a. Disponível em: <http://www.prdhs.ufsc.br/>. Acesso em: 14 fev. 2012.

SEPLAN - Secretaria de Planejamento e Finanças. 2012b. Disponível em: $<\mathrm{http}: / /$ www.seplan.ufsc.br/contatos/secretario/>. Acesso em: 11 abr. 2012.

ZARIFIAN, Philippe. Objetivo competência: por uma nova lógica. São Paulo: Atlas, 2001. 